\title{
Coupled Coincidence Point Theorems for Nonlinear Contractions in Partially Ordered Quasi-Metric Spaces with a $Q$-Function
}

\author{
N. Hussain, ${ }^{1}$ M. H. Shah, ${ }^{2}$ and M. A. Kutbi ${ }^{1}$ \\ ${ }^{1}$ Department of Mathematics, King Abdulaziz University, P.O. Box 80203, Jeddah 21589, Saudi Arabia \\ ${ }^{2}$ Department of Mathematical Sciences, LUMS, DHA Lahore, Lahore 54792, Pakistan
}

Correspondence should be addressed to N. Hussain, nhusain@kau.edu.sa

Received 20 August 2010; Accepted 16 September 2010

Academic Editor: Qamrul Hasan Ansari

Copyright (C) 2011 N. Hussain et al. This is an open access article distributed under the Creative Commons Attribution License, which permits unrestricted use, distribution, and reproduction in any medium, provided the original work is properly cited.

Using the concept of a mixed g-monotone mapping, we prove some coupled coincidence and coupled common fixed point theorems for nonlinear contractive mappings in partially ordered complete quasi-metric spaces with a $Q$-function $q$. The presented theorems are generalizations of the recent coupled fixed point theorems due to Bhaskar and Lakshmikantham (2006), Lakshmikantham and Ćirić (2009) and many others.

\section{Introduction}

The Banach contraction principle is the most celebrated fixed point theorem and has been generalized in various directions (cf. [1-31]). Recently, Bhaskar and Lakshmikantham [8], Nieto and Rodríguez-López [28, 29], Ran and Reurings [30], and Agarwal et al. [1] presented some new results for contractions in partially ordered metric spaces. Bhaskar and Lakshmikantham [8] noted that their theorem can be used to investigate a large class of problems and discussed the existence and uniqueness of solution for a periodic boundary value problem. For more on metric fixed point theory, the reader may consult the book [22].

Recently, Al-Homidan et al. [2] introduced the concept of a $Q$-function defined on a quasi-metric space which generalizes the notions of a $\tau$-function and a $\omega$-distance and establishes the existence of the solution of equilibrium problem (see also [3-7]). The aim of this paper is to extend the results of Lakshmikantham and Cirić [24] for a mixed monotone nonlinear contractive mapping in the setting of partially ordered quasi-metric spaces with a $Q$-function $q$. We prove some coupled coincidence and coupled common fixed point theorems for a pair of mappings. Our results extend the recent coupled fixed point theorems due to Lakshmikantham and Ćirić [24] and many others. 
Recall that if $(X, \leq)$ is a partially ordered set and $F: X \rightarrow X$ such that for $x, y \in X, x \leq y$ implies $F(x) \leq F(y)$, then a mapping $F$ is said to be nondecreasing. Similarly, a nonincreasing mapping is defined. Bhaskar and Lakshmikantham [8] introduced the following notions of a mixed monotone mapping and a coupled fixed point.

Definition 1.1 (Bhaskar and Lakshmikantham [8]). Let $(X, \leq)$ be a partially ordered set and $F: X \times X \rightarrow X$. The mapping $F$ is said to have the mixed monotone property if $F$ is nondecreasing monotone in its first argument and is nonincreasing monotone in its second argument, that is, for any $x, y \in X$,

$$
\begin{aligned}
& x_{1}, x_{2} \in X, \quad x_{1} \leq x_{2} \Longrightarrow F\left(x_{1}, y\right) \leq F\left(x_{2}, y\right) \\
& y_{1}, y_{2} \in X, \quad y_{1} \leq y_{2} \Longrightarrow F\left(x, y_{1}\right) \geq F\left(x, y_{2}\right) .
\end{aligned}
$$

Definition 1.2 (Bhaskar and Lakshmikantham [8]). An element $(x, y) \in X \times X$ is called a coupled fixed point of the mapping $F: X \times X \rightarrow X$ if

$$
F(x, y)=x, \quad F(y, x)=y .
$$

The main theoretical result of Lakshmikantham and Ćirić in [24] is the following coupled fixed point theorem.

Theorem 1.3 (Lakshmikantham and Cirić [24, Theorem 2.1]). Let $(X, \leq)$ be a partially ordered set, and suppose, there is a metric $d$ on $X$ such that $(X, d)$ is a complete metric space. Assume there is a function $\varphi:[0,+\infty) \rightarrow[0,+\infty)$ with $\varphi(t)<t$ and $\lim _{r \rightarrow t+} \varphi(r)<t$ for each $t>0$, and also suppose that $F: X \times X \rightarrow X$ and $g: X \rightarrow X$ such that $F$ has the mixed $g$-monotone property and

$$
d(F(x, y), F(u, v)) \leq \varphi\left(\frac{d(g(x), g(u))+d(g(y), g(v))}{2}\right)
$$

for all $x, y, u, v \in X$ for which $g(x) \leq g(u)$ and $g(y) \geq g(v)$. Suppose that $F(X \times X) \subseteq g(X)$, and $g$ is continuous and commutes with $F$, and also suppose that either

(a) $F$ is continuous or

(b) X has the following property:

(i) if a nondecreasing sequence $\left\{x_{n}\right\} \rightarrow x$, then $x_{n} \leq x$ for all $n$,

(ii) if a nonincreasing sequence $\left\{y_{n}\right\} \rightarrow y_{\text {, then }} y \leq y_{n}$ for all $n$.

If there exists $x_{0}, y_{0} \in X$ such that

$$
g\left(x_{0}\right) \leq F\left(x_{0}, y_{0}\right), \quad g\left(y_{0}\right) \geq F\left(y_{0}, x_{0}\right),
$$

then there exist $x, y \in X$ such that

$$
g(x)=F(x, y), \quad g(y)=F(y, x),
$$

that is, $F$ and $g$ have a coupled coincidence. 
Definition 1.4. Let $X$ be a nonempty set. A real-valued function $d: X \times X \rightarrow \mathbb{R}^{+}$is said to be quasi-metric on $X$ if

$$
\begin{aligned}
& \left(M_{1}\right) d(x, y) \geq 0 \text { for all } x, y \in X, \\
& \left(M_{2}\right) d(x, y)=0 \text { if and only if } x=y, \\
& \left(M_{3}\right) d(x, y) \leq d(x, z)+d(z, y) \text { for all } x, y, z \in X .
\end{aligned}
$$

The pair $(X, d)$ is called a quasi-metric space.

Definition 1.5. Let $(X, d)$ be a quasi-metric space. A mapping $q: X \times X \rightarrow \mathbb{R}^{+}$is called a $Q$-function on $X$ if the following conditions are satisfied:

$\left(Q_{1}\right)$ for all $x, y, z \in X$,

$\left(Q_{2}\right)$ if $x \in X$ and $\left(y_{n}\right)_{n \geq 1}$ is a sequence in $X$ such that it converges to a point $y$ (with respect to the quasi-metric) and $q\left(x, y_{n}\right) \leq M$ for some $M=M(x)$, then $q(x, y) \leq$ $M$;

$\left(Q_{3}\right)$ for any $\epsilon>0$, there exists $\delta>0$ such that $q(z, x) \leq \delta$, and $q(z, y) \leq \delta$ implies that $d(x, y) \leq \epsilon$.

Remark 1.6 (see [2]). If $(X, d)$ is a metric space, and in addition to $\left(Q_{1}\right)-\left(Q_{3}\right)$, the following condition is also satisfied:

$\left(Q_{4}\right)$ for any sequence $\left(x_{n}\right)_{n \geq 1}$ in $X$ with $\lim _{n \rightarrow \infty} \sup \left\{q\left(x_{n}, x_{m}\right): m>n\right\}=0$ and if there exists a sequence $\left(y_{n}\right)_{n \geq 1}$ in $X$ such that $\lim _{n \rightarrow \infty} q\left(x_{n}, y_{n}\right)=0$, then $\lim _{n \rightarrow \infty} d\left(x_{n}, y_{n}\right)=0$,

then a $Q$-function is called a $\tau$-function, introduced by Lin and Du [27]. It has been shown in [27] that every $w$-distance or $w$-function, introduced and studied by Kada et al. [21], is a $\tau$-function. In fact, if we consider $(X, d)$ as a metric space and replace $\left(Q_{2}\right)$ by the following condition:

$\left(Q_{5}\right)$ for any $x \in X$, the function $p(x, \cdot) \rightarrow \mathbb{R}^{+}$is lower semicontinuous,

then a $Q$-function is called a $w$-distance on $X$. Several examples of $w$-distance are given in [21]. It is easy to see that if $q(x, \cdot)$ is lower semicontinuous, then $\left(Q_{2}\right)$ holds. Hence, it is obvious that every $w$-function is a $\tau$-function and every $\tau$-function is a $Q$-function, but the converse assertions do not hold.

Example 1.7 (see [2]). (a) Let $X=\mathbb{R}$. Define $d: X \times X \rightarrow \mathbb{R}^{+}$by

$$
d(x, y)= \begin{cases}0, & \text { if } x=y \\ |y|, & \text { otherwise }\end{cases}
$$

and $q: X \times X \rightarrow \mathbb{R}^{+}$by

$$
q(x, y)=|y|, \quad \forall x, y \in X
$$

Then one can easily see that $d$ is a quasi-metric and $q$ is a $Q$-function on $X$, but $q$ is neither a $\tau$-function nor a $w$-function. 
(b) Let $X=[0,1]$. Define $d: X \times X \rightarrow \mathbb{R}^{+}$by

$$
d(x, y)= \begin{cases}y-x, & \text { if } x \leq y \\ 2(x-y), & \text { otherwise }\end{cases}
$$

and $q: X \times X \rightarrow \mathbb{R}^{+}$by

$$
q(x, y)=|x-y|, \quad \forall x, y \in X \text {. }
$$

Then $q$ is a $Q$-function on $X$. However, $q$ is neither a $\tau$-function nor a $w$-function, because $(X, d)$ is not a metric space.

The following lemma lists some properties of a $Q$-function on $X$ which are similar to that of a $w$-function (see [21]).

Lemma 1.8 (see [2]). Let $q: X \times X \rightarrow \mathbb{R}^{+}$be a $Q$-function on $X$. Let $\left\{x_{n}\right\}_{n \in \mathbb{N}}$ and $\left\{y_{n}\right\}_{n \in \mathbb{N}}$ be sequences in $X$, and let $\left\{\alpha_{n}\right\}_{n \in \mathbb{N}}$ and $\left\{\beta_{n}\right\}_{n \in \mathbb{N}}$ be such that they converge to 0 and $x, y, z \in X$. Then, the following hold:

(1) if $q\left(x_{n}, y\right) \leq \alpha_{n}$ and $q\left(x_{n}, z\right) \leq \beta_{n}$ for all $n \in N$, then $y=z$. In particular, if $q(x, y)=0$ and $q(x, z)=0$, then $y=z$;

(2) if $q\left(x_{n}, y_{n}\right) \leq \alpha_{n}$ and $q\left(x_{n}, z\right) \leq \beta_{n}$ for all $n \in N$, then $\left\{y_{n}\right\}_{n \in \mathbb{N}}$ converges to $z$;

(3) if $q\left(x_{n}, x_{m}\right) \leq \alpha_{n}$ for all $n, m \in N$ with $m>n$, then $\left\{x_{n}\right\}_{n \in \mathbb{N}}$ is a Cauchy sequence;

(4) if $q\left(y, x_{n}\right) \leq \alpha_{n}$ for all $n \in N$, then $\left\{x_{n}\right\}_{n \in \mathbb{N}}$ is a Cauchy sequence;

(5) if $q_{1}, q_{2}, q_{3}, \ldots, q_{n}$ are $Q$-functions on $X$, then $q(x, y)=\max \left\{q_{1}(x, y), q_{2}(x, y), \ldots\right.$, $\left.q_{n}(x, y)\right\}$ is also a $Q$-function on $X$.

\section{Main Results}

Analogous with Definition 1.1, Lakshmikantham and Cirić [24] introduced the following concept of a mixed $g$-monotone mapping.

Definition 2.1 (Lakshmikantham and Ćirić [24]). Let $(X, \leq)$ be a partially ordered set, and $F: X \times X \rightarrow X$ and $g: X \rightarrow X$. We say $F$ has the mixed $g$-monotone property if $F$ is nondecreasing $g$-monotone in its first argument and is nondecreasing $g$-monotone in its second argument, that is, for any $x, y \in X$,

$$
\begin{array}{ll}
x_{1}, x_{2} \in X, & g\left(x_{1}\right) \leq g\left(x_{2}\right) \text { implies } F\left(x_{1}, y\right) \leq F\left(x_{2}, y\right) \\
y_{1}, y_{2} \in X, & g\left(y_{1}\right) \leq g\left(y_{2}\right) \text { implies } F\left(x, y_{1}\right) \geq F\left(x, y_{2}\right)
\end{array}
$$

Note that if $g$ is the identity mapping, then Definition 2.1 reduces to Definition 1.1. 
Definition 2.2 (see [24]). An element $(x, y) \in X \times X$ is called a coupled coincidence point of a mapping $F: X \times X \rightarrow X$ and $g: X \rightarrow X$ if

$$
F(x, y)=g(x), \quad F(y, x)=g(y)
$$

Definition 2.3 (see [24]). Let $X$ be a nonempty set and $F: X \times X \rightarrow X$ and $g: X \rightarrow X$. one says $F$ and $g$ are commutative if

$$
g(F(x, y))=F(g(x), g(y))
$$

for all $x, y \in X$.

Following theorem is the main result of this paper.

Theorem 2.4. Let $(X, \leq, d)$ be a partially ordered complete quasi-metric space with a $Q$-function $q$ on $X$. Assume that the function $\varphi:[0,+\infty) \rightarrow[0,+\infty)$ is such that

$$
\varphi(t)<t, \quad \text { for each } t>0 \text {. }
$$

Further, suppose that $k \in(0,1)$ and $F: X \times X \rightarrow X ; g: X \rightarrow X$ are such that $F$ has the mixed $g$-monotone property and

$$
q(F(x, y), F(u, v)) \leq k \varphi\left(\frac{q(g(x), g(u))+q(g(y), g(v))}{2}\right)
$$

for all $x, y, u, v \in X$ for which $g(x) \leq g(u)$ and $g(y) \geq g(v)$. Suppose that $F(X \times X) \subseteq g(X)$, and $g$ is continuous and commutes with $F$, and also suppose that either

(a) $F$ is continuous or

(b) X has the following property:

(i) if a nondecreasing sequence $\left\{x_{n}\right\} \rightarrow x$, then $x_{n} \leq x$ for all $n$,

(ii) if a nonincreasing sequence $\left\{y_{n}\right\} \rightarrow y_{\text {, then }} y \leq y_{n}$ for all $n$.

If there exists $x_{0}, y_{0} \in X$ such that

$$
g\left(x_{0}\right) \leq F\left(x_{0}, y_{0}\right), \quad g\left(y_{0}\right) \geq F\left(y_{0}, x_{0}\right),
$$

then there exist $x, y \in X$ such that

$$
g(x)=F(x, y), \quad g(y)=F(y, x),
$$

that is, $F$ and $g$ have a coupled coincidence. 
Proof. Choose $x_{0}, y_{0} \in X$ to be such that $g\left(x_{0}\right) \leq F\left(x_{0}, y_{0}\right)$ and $g\left(y_{0}\right) \geq F\left(y_{0}, x_{0}\right)$. Since $F(X \times$ $X) \subseteq g(X)$, we can choose $x_{1}, y_{1} \in X$ such that $g\left(x_{1}\right)=F\left(x_{0}, y_{0}\right)$ and $g\left(y_{1}\right)=F\left(y_{0}, x_{0}\right)$. Again from $F(X \times X) \subseteq g(X)$, we can choose $x_{2}, y_{2} \in X$ such that $g\left(x_{2}\right)=F\left(x_{1}, y_{1}\right)$ and $g\left(y_{2}\right)=F\left(y_{1}, x_{1}\right)$. Continuing this process, we can construct sequences $\left\{x_{n}\right\}$ and $\left\{y_{n}\right\}$ in $X$ such that

$$
g\left(x_{n+1}\right)=F\left(x_{n}, y_{n}\right), \quad g\left(y_{n+1}\right)=F\left(y_{n}, x_{n}\right), \quad \forall n \geq 0
$$

We will show that

$$
\begin{aligned}
& g\left(x_{n}\right) \leq g\left(x_{n+1}\right), \quad \forall n \geq 0, \\
& g\left(y_{n}\right) \geq g\left(y_{n+1}\right), \quad \forall n \geq 0 .
\end{aligned}
$$

We will use the mathematical induction. Let $n=0$. Since $g\left(x_{0}\right) \leq F\left(x_{0}, y_{0}\right)$ and $g\left(y_{0}\right) \geq$ $F\left(y_{0}, x_{0}\right)$, and as $g\left(x_{1}\right)=F\left(x_{0}, y_{0}\right)$ and $g\left(y_{1}\right)=F\left(y_{0}, x_{0}\right)$, we have $g\left(x_{0}\right) \leq g\left(x_{1}\right)$ and $g\left(y_{0}\right) \geq$ $g\left(y_{1}\right)$. Thus, (2.9) and (2.10) hold for $n=0$. Suppose now that (2.9) and (2.10) hold for some fixed $n \geq 0$. Then, since $g\left(x_{n}\right) \leq g\left(x_{n+1}\right)$ and $g\left(y_{n+1}\right) \leq g\left(y_{n}\right)$, and as $F$ has the mixed $g$ monotone property, from (2.8) and (2.9),

$$
g\left(x_{n+1}\right)=F\left(x_{n}, y_{n}\right) \leq F\left(x_{n+1}, y_{n}\right), \quad F\left(y_{n+1}, x_{n}\right) \leq F\left(y_{n}, x_{n}\right)=g\left(y_{n+1}\right),
$$

and from (2.8) and (2.10),

$$
g\left(x_{n+2}\right)=F\left(x_{n+1}, y_{n+1}\right) \geq F\left(x_{n+1}, y_{n}\right), \quad F\left(y_{n+1}, x_{n}\right) \geq F\left(y_{n+1}, x_{n+1}\right)=g\left(y_{n+2}\right) .
$$

Now from (2.11) and (2.12), we get

$$
\begin{aligned}
& g\left(x_{n+1}\right) \leq g\left(x_{n+2}\right), \\
& g\left(y_{n+1}\right) \geq g\left(y_{n+2}\right) .
\end{aligned}
$$

Thus, by the mathematical induction, we conclude that (2.9) and (2.10) hold for all $n \geq 0$. Therefore,

$$
\begin{aligned}
& g\left(x_{0}\right) \leq g\left(x_{1}\right) \leq g\left(x_{2}\right) \leq g\left(x_{3}\right) \leq \cdots \leq g\left(x_{n}\right) \leq g\left(x_{n+1}\right) \leq \cdots, \\
& g\left(y_{0}\right) \geq g\left(y_{1}\right) \geq g\left(y_{2}\right) \geq g\left(y_{3}\right) \geq \cdots \geq g\left(y_{n}\right) \geq g\left(y_{n+1}\right) \geq \cdots
\end{aligned}
$$


Denote

$$
\delta_{n}=q\left(g\left(x_{n}\right), g\left(x_{n+1}\right)\right)+q\left(g\left(y_{n}\right), g\left(y_{n+1}\right)\right)
$$

We show that

$$
\delta_{n} \leq 2 k \varphi\left(\frac{\delta_{n-1}}{2}\right)
$$

Since $g\left(x_{n-1}\right) \leq g\left(x_{n}\right)$ and $g\left(y_{n-1}\right) \geq g\left(y_{n}\right)$, from (2.11) and (2.5), we have

$$
\begin{aligned}
q\left(g\left(x_{n}\right), g\left(x_{n+1}\right)\right) & =q\left(F\left(x_{n-1}, y_{n-1}\right), F\left(x_{n}, y_{n}\right)\right) \\
& \leq k \varphi\left(\frac{q\left(g\left(x_{n-1}\right), g\left(x_{n}\right)\right)+q\left(g\left(y_{n-1}\right), g\left(y_{n}\right)\right)}{2}\right) \\
& =k \varphi\left(\frac{\delta_{n-1}}{2}\right) .
\end{aligned}
$$

Similarly, from (2.11) and (2.5), as $g\left(y_{n}\right) \leq g\left(y_{n-1}\right)$ and $g\left(x_{n}\right) \geq g\left(x_{n-1}\right)$,

$$
\begin{aligned}
q\left(g\left(y_{n+1}\right), g\left(y_{n}\right)\right) & =q\left(F\left(y_{n}, x_{n}\right), F\left(y_{n-1}, x_{n-1}\right)\right) \\
& \leq k \varphi\left(\frac{q\left(g\left(y_{n-1}\right), g\left(y_{n}\right)\right)+q\left(g\left(x_{n-1}\right), g\left(x_{n}\right)\right)}{2}\right) \\
& =k \varphi\left(\frac{\delta_{n-1}}{2}\right) .
\end{aligned}
$$

Adding (2.17) and (2.18), we obtain (2.16). Since $\varphi(t)<t$ for $t>0$, it follows, from (2.16), that

$$
0 \leq \delta_{n} \leq k \delta_{n-1} \leq k^{2} \delta_{n-2} \leq \cdots \leq k^{n} \delta_{0}
$$

and so, by squeezing, we get

$$
\lim _{n \rightarrow \infty} \delta_{n}=0
$$

Thus,

$$
\lim _{n \rightarrow \infty}\left[q\left(g\left(x_{n}\right), g\left(x_{n+1}\right)\right)+q\left(g\left(y_{n}\right), g\left(y_{n+1}\right)\right)\right]=\lim _{n \rightarrow \infty} \delta_{n}=0
$$


Now, we prove that $\left\{g\left(x_{n}\right)\right\}$ and $\left\{g\left(y_{n}\right)\right\}$ are Cauchy sequences. For $m>n$, and since $\varphi(t)<t$ for each $t>0$, we have

$$
\begin{aligned}
\delta_{n m}= & q\left(g\left(x_{n}\right), g\left(x_{m}\right)\right)+q\left(g\left(y_{n}\right), g\left(y_{m}\right)\right) \\
\leq & {\left[q\left(g\left(x_{n}\right), g\left(x_{n+1}\right)\right)+q\left(g\left(y_{n}\right), g\left(y_{n+1}\right)\right)\right] } \\
& +\left[q\left(g\left(x_{n+1}\right), g\left(x_{n+2}\right)\right)+q\left(g\left(y_{n+1}\right), g\left(y_{n+2}\right)\right)\right] \\
& +\cdots+\left[q\left(g\left(x_{m-1}\right), g\left(x_{m}\right)\right)+q\left(g\left(y_{m-1}\right), g\left(y_{m}\right)\right)\right] \\
= & \delta_{n}+\delta_{n+1}+\delta_{n+2}+\cdots+\delta_{m-1} \\
\leq & \delta_{n}+2 k \varphi\left(\frac{\delta_{n}}{2}\right)+2 k \varphi\left(\frac{\delta_{n+1}}{2}\right)+\cdots+2 k \varphi\left(\frac{\delta_{m-2}}{2}\right) \\
\leq & \delta_{n}+2 k\left(\frac{\delta_{n}}{2}+\frac{\delta_{n+1}}{2}+\cdots+\frac{\delta_{m-2}}{2}\right) \\
\leq & \delta_{n}+k\left(\delta_{n}+\delta_{n+1}+\delta_{n+2}+\cdots\right) \\
\leq & \delta_{n}+k\left(\delta_{n}+2 k \varphi\left(\frac{\delta_{n}}{2}\right)+2 k \varphi\left(\frac{\delta_{n+1}}{2}\right)+\cdots\right) \\
\leq & \delta_{n}+k\left(\delta_{n}+k \delta_{n}+k \delta_{n+1}+\cdots\right) \\
\leq & \delta_{n}+k\left(\delta_{n}+k \delta_{n}+k^{2} \delta_{n}+k^{3} \delta_{n}+\cdots\right) \\
= & \delta_{n}\left(1+k+k^{2}+k^{3}+\cdots\right) \\
= & \left(\frac{1}{1-k}\right) \delta_{n}=\lambda \delta_{n} \rightarrow 0, \text { as } \longrightarrow \infty\left(\lambda=\frac{1}{1-k}\right) .
\end{aligned}
$$

This means that for $m>n>n_{0}$,

$$
q\left(g\left(x_{n}\right), g\left(x_{m}\right)\right) \leq \lambda \delta_{n}, \quad q\left(g\left(y_{n}\right), g\left(y_{m}\right)\right) \leq \lambda \delta_{n} .
$$

Therefore, by Lemma 1.8, $\left\{g\left(x_{n}\right)\right\}$ and $\left\{g\left(y_{n}\right)\right\}$ are Cauchy sequences. Since $X$ is complete, there exists $x, y \in X$ such that

$$
\lim _{n \rightarrow \infty} g\left(x_{n}\right)=x, \quad \lim _{n \rightarrow \infty} g\left(y_{n}\right)=y,
$$

and (2.24) combined with the continuity of $g$ yields

$$
\lim _{n \rightarrow \infty} g\left(g\left(x_{n}\right)\right)=g(x), \quad \lim _{n \rightarrow \infty} g\left(g\left(y_{n}\right)\right)=g(y)
$$


From (2.11) and commutativity of $F$ and $g$,

$$
\begin{aligned}
& g\left(g\left(x_{n+1}\right)\right)=g\left(F\left(x_{n}, y_{n}\right)\right)=F\left(g\left(x_{n}\right), g\left(y_{n}\right)\right), \\
& g\left(g\left(y_{n+1}\right)\right)=g\left(F\left(y_{n}, x_{n}\right)\right)=F\left(g\left(y_{n}\right), g\left(x_{n}\right)\right) .
\end{aligned}
$$

We now show that $g(x)=F(x, y)$ and $g(y)=F(y, x)$.

Case 1. Suppose that the assumption (a) holds. Taking the limit as $n \rightarrow \infty$ in (2.26), and using the continuity of $F$, we get

$$
\begin{aligned}
& g(x)=\lim _{n \rightarrow \infty} g\left(g\left(x_{n+1}\right)\right)=\lim _{n \rightarrow \infty} F\left(g\left(x_{n}\right), g\left(y_{n}\right)\right)=F\left(\lim _{n \rightarrow \infty} g\left(x_{n}\right), \lim _{n \rightarrow \infty} g\left(y_{n}\right)\right)=F(x, y), \\
& g(y)=\lim _{n \rightarrow \infty} g\left(g\left(y_{n+1}\right)\right)=\lim _{n \rightarrow \infty} F\left(g\left(y_{n}\right), g\left(x_{n}\right)\right)=F\left(\lim _{n \rightarrow \infty} g\left(y_{n}\right), \lim _{n \rightarrow \infty} g\left(x_{n}\right)\right)=F(y, x) .
\end{aligned}
$$

Thus,

$$
g(x)=F(x, y), \quad g(y)=F(y, x)
$$

Case 2. Suppose that the assumption (b) holds. Let $h(x)=g g(x)$. Now, since $g$ is continuous, $\left\{g\left(x_{n}\right)\right\}$ is nondecreasing with $g\left(x_{n}\right) \rightarrow x, g\left(x_{n}\right) \leq x$ for all $n \in \mathbb{N}$, and $\left\{g\left(y_{n}\right)\right\}$ is nonincreasing with $g\left(y_{n}\right) \rightarrow y, g\left(y_{n}\right) \geq y$ for all $n \in \mathbb{N}$, so $\left(h\left(x_{n}\right)\right)_{n \geq 1}$ is nondecreasing, that is,

$$
h\left(x_{0}\right) \leq h\left(x_{1}\right) \leq h\left(x_{2}\right) \leq h\left(x_{3}\right) \leq \cdots \leq h\left(x_{n}\right) \leq h\left(x_{n+1}\right) \leq \cdots
$$

with $h\left(x_{n}\right)=g g\left(x_{n}\right) \rightarrow g(x), h\left(x_{n}\right) \leq g(x)$ for all $n \in \mathbb{N}$, and $\left(h\left(y_{n}\right)\right)_{n \geq 1}$ is nonincreasing, that is,

$$
h\left(y_{0}\right) \geq h\left(y_{1}\right) \geq h\left(y_{2}\right) \geq h\left(y_{3}\right) \geq \cdots \geq h\left(y_{n}\right) \geq h\left(y_{n+1}\right) \geq \cdots
$$

with $h\left(y_{n}\right)=g g\left(y_{n}\right) \rightarrow g(y), h\left(y_{n}\right) \geq g(y)$ for all $n \in \mathbb{N}$.

Let

$$
\gamma_{n}=q\left(h\left(x_{n}\right), h\left(x_{n+1}\right)\right)+q\left(h\left(y_{n}\right), h\left(y_{n+1}\right)\right)
$$

Then replacing $g$ by $h$ and $\delta$ by $\gamma$ in (2.16), we get $\gamma_{n} \leq 2 k \varphi\left(\gamma_{n-1} / 2\right)$ such that $\lim _{n \rightarrow \infty} \gamma_{n}=0$. We show that

$$
\begin{aligned}
& \lim _{n \rightarrow \infty} q\left(h\left(x_{n}\right), g(x)\right)+q\left(h\left(y_{n}\right), g(y)\right)=0, \\
& \lim _{n \rightarrow \infty} q\left(h\left(x_{n}\right), F(x, y)\right)+q\left(h\left(y_{n}\right), F(y, x)\right)=0 .
\end{aligned}
$$


In $\delta_{n m}$, replacing $g$ by $h$ and $\delta$ by $\gamma$, we get

$$
q\left(h\left(x_{n}\right), h\left(x_{m}\right)\right)+q\left(h\left(y_{n}\right), h\left(y_{m}\right)\right) \leq \lambda \gamma_{n} \longrightarrow 0, \quad \text { as } n \longrightarrow \infty,
$$

that is, for $m>n>n_{0}$,

$$
q\left(h\left(x_{n}\right), h\left(x_{m}\right)\right) \leq \lambda \gamma_{n}, \quad q\left(h\left(y_{n}\right), h\left(y_{m}\right)\right) \leq \frac{\lambda \gamma_{n}}{2}
$$

or for $m>n=n_{0}+1$,

$$
\begin{gathered}
q\left(h\left(x_{n_{0}+1}\right), h\left(x_{m}\right)\right) \leq \lambda \gamma_{n_{0}+1}, \\
q\left(h\left(y_{n_{0}+1}\right), h\left(y_{m}\right)\right) \leq \frac{\lambda \gamma_{n_{0}+1}}{2} .
\end{gathered}
$$

Let $M_{g(x)}=\lambda \gamma_{n_{0}+1}$, and $M_{g(y)}=(\lambda / 2) \gamma_{n_{0}+1}$. Then, since $h\left(x_{m}\right) \rightarrow g(x), h\left(y_{m}\right) \rightarrow g(y)$, and $h\left(x_{n_{0}+1}\right), h\left(y_{n_{0}+1}\right) \in X$, by axiom $\left(Q_{2}\right)$ of the $Q$-function, we get

$$
q\left(h\left(x_{n_{0}+1}\right), g(x)\right) \leq M_{g(x)}, \quad q\left(h\left(y_{n_{0}+1}\right), g(y)\right) \leq M_{g(y)} .
$$

Therefore, by the triangle inequality and $(*)$, we have (for $n>n_{0}$ )

Case 3.

$$
\begin{aligned}
q\left(h\left(x_{n}\right), g(x)\right)+q\left(h\left(y_{n}\right), g(y)\right) \leq & {\left[q\left(h\left(x_{n}\right), h\left(x_{n+1}\right)\right)+q\left(h\left(y_{n}\right), h\left(y_{n+1}\right)\right)\right] } \\
& +\left[q\left(h\left(x_{n+1}\right), g(x)\right)+q\left(h\left(y_{n+1}\right), g(y)\right)\right] \\
\leq & \gamma_{n}+M_{g(x)}+M_{g(y)} .
\end{aligned}
$$

This implies that

$$
\begin{gathered}
q\left(h\left(x_{n}\right), g(x)\right) \leq \gamma_{n}+M_{g(x)}+M_{g(y)}, \\
q\left(h\left(y_{n}\right), g(y)\right) \leq \gamma_{n}+M_{g(x)}+M_{g(y)} .
\end{gathered}
$$


Fixed Point Theory and Applications

Case 4. Also, we have

$$
\begin{aligned}
q\left(h\left(x_{n}\right), F(x, y)\right)+p\left(h\left(y_{n}\right), F(y, x)\right) \\
\leq\left[q\left(h\left(x_{n}\right), h\left(x_{n+1}\right)\right)+q\left(h\left(y_{n}\right), h\left(y_{n+1}\right)\right)\right] \\
+\left[q\left(h\left(x_{n+1}\right), F(x, y)\right)+q\left(h\left(y_{n+1}\right), F(y, x)\right)\right] \\
=\gamma_{n}+\left[q\left(F\left(g\left(x_{n}\right), g\left(y_{n}\right)\right), F(x, y)\right)\right. \\
\left.\quad+q\left(F\left(g\left(y_{n}\right), g\left(x_{n}\right)\right), F(y, x)\right)\right] \\
\leq \gamma_{n}+k \varphi\left(\frac{q\left(g g\left(x_{n}\right), g(x)\right)+q\left(g g\left(y_{n}\right), g(y)\right)}{2}\right) \\
+k \varphi\left(\frac{q\left(g g\left(y_{n}\right), g(y)\right)+q\left(g g\left(x_{n}\right), g(x)\right)}{2}\right)
\end{aligned}
$$

or

$$
\begin{aligned}
q\left(h\left(x_{n}\right), F(x, y)\right)+q\left(h\left(y_{n}\right), F(y, x)\right) \\
=\gamma_{n}+k \varphi\left(\frac{q\left(h\left(x_{n}\right), g(x)\right)+q\left(h\left(y_{n}\right), g(y)\right)}{2}\right) \\
\quad+k \varphi\left(\frac{q\left(h\left(y_{n}\right), g(y)\right)+q\left(h\left(x_{n}\right), g(x)\right)}{2}\right) \\
=\gamma_{n}+2 k \varphi\left(\frac{q\left(h\left(x_{n}\right), g(x)\right)+q\left(h\left(y_{n}\right), g(y)\right)}{2}\right) \\
\leq \gamma_{n}+k\left(q\left(h\left(x_{n}\right), g(x)\right)+q\left(h\left(y_{n}\right), g(y)\right)\right) \\
\leq \gamma_{n}+k\left(\gamma_{n}+M_{g(x)}+M_{g(y)}\right)(\text { by }(* *)) \\
=\mu \gamma_{n}, \quad \text { where } \mu=1+k\left(1+\lambda+\frac{\lambda}{2}\right) .
\end{aligned}
$$

That is, for $n>n_{0}$,

$$
q\left(h\left(x_{n}\right), F(x, y)\right) \leq \mu \gamma_{n}, \quad q\left(h\left(y_{n}\right), F(y, x)\right) \leq \mu \gamma_{n}
$$

Hence, by Lemma 1.8, $g(x)=F(x, y)$ and $g(y)=F(y, x)$. Thus, $F$ and $g$ have a coupled coincidence point.

The following example illustrates Theorem 2.4. 
Example 2.5. Let $X=[0, \infty)$ with the usual partial order $\leq$. Define $d: X \times X \rightarrow \mathbb{R}^{+}$by

$$
d(x, y)= \begin{cases}y-x, & \text { if } x \leq y \\ 2(x-y), & \text { otherwise }\end{cases}
$$

and $q: X \times X \rightarrow \mathbb{R}^{+}$by

$$
q(x, y)=|x-y|, \quad \forall x, y \in X
$$

Then $d$ is a quasi-metric and $q$ is a $Q$-function on $X$. Thus, $(X, \leq, d)$ is a partially ordered complete quasi-metric space with a $Q$-function $q$ on $X$. Let $\varphi(t)=t / 2$, for $t>0$. Define $F: X \times X \rightarrow X$ by

$$
F(x, y)= \begin{cases}\frac{x-y}{5}, & \text { if } x \geq y \\ 0, & \text { if } x<y\end{cases}
$$

and $g: X \rightarrow X$ by $g(x)=5 x / k$, where $0<k<1$. Then, $F$ has the mixed $g$-monotone property with

$$
g(F(x, y))=\left\{\begin{array}{cc}
\frac{x-y}{k}, & \text { if } x \geq y \\
0, & \text { if } x<y,
\end{array}\right\}=F(g(x), g(y))
$$

and $F, g$ are both continuous on their domains and $F(X \times X) \subseteq g(X)$. Let $x, y, u, v \in X$ be such that $g(x) \leq g(u)$ and $g(y) \geq g(v)$. There are four possibilities for (2.5) to hold. We first compute expression on the left of (2.5) for these cases:

(i) $x \geq$ and $u \geq v$,

$$
\begin{aligned}
q(F(x, y), F(u, v)) & =|F(x, y)-F(u, v)| \\
& =\left|\frac{(x-y)}{5}-\frac{(u-v)}{5}\right| \\
& =\frac{1}{5}|(x-u)-(y-v)| \\
& \leq \frac{1}{5}\{|x-u|+|y-v|\} .
\end{aligned}
$$


Fixed Point Theory and Applications

(ii) $x \geq y$ and $u<v$,

$$
\begin{aligned}
q(F(x, y), F(u, v)) & =|F(x, y)-0| \\
& =\left|\frac{(x-y)}{5}\right| \\
& =\frac{1}{5}|(x-u)-(y-u)| \\
& \leq \frac{1}{5}|(x-u)-(y-v)|(u<v) \\
& \leq \frac{1}{5}\{|x-u|+|y-v|\} .
\end{aligned}
$$

(iii) $x<y$ and $u \geq v$,

$$
\begin{aligned}
q(F(x, y), F(u, v)) & =|0-F(u, v)| \\
& =\left|\frac{(u-v)}{5}\right| \\
& =\frac{1}{5}|(u-x)+(x-v)| \\
& \leq \frac{1}{5}|(u-x)+(y-v)|(x<y) \\
& \leq \frac{1}{5}\{|x-u|+|y-v|\} .
\end{aligned}
$$

(iv) $x<y$ and $u<v$,

$$
q(F(x, y), F(u, v))=|0-0|=0 .
$$

On the other hand, (in all the above four cases), we have

$$
\begin{aligned}
k \varphi( & \left.\frac{q(g(x), g(u))+q(g(y), g(v))}{2}\right) \\
& =k \frac{(q(g(x), g(u))+q(g(y), g(v))) / 2}{2} \\
& =\frac{k}{4}\left\{\frac{5}{k}(|x-u|+|y-v|)\right\} \\
& =\frac{5}{4}\{|x-u|+|y-v|\} .
\end{aligned}
$$


Thus, $F$ satisfies the contraction condition (2.5) of Theorem 2.4. Now, suppose that $\left(x_{n}\right)_{n \geq 1} ;\left(y_{n}\right)_{n \geq 1}$ be, respectively, nondecreasing and nonincreasing sequences such that $x_{n} \rightarrow$ $x$ and $y_{n} \rightarrow y$, then by Theorem 2.4, $x_{n} \leq x$ and $y_{n} \geq y$ for all $n \geq 1$.

Let $x_{0}=0, y_{0}=5 k$. Then, this point satisfies the relations

$$
g\left(x_{0}\right)=0=F\left(x_{0}, y_{0}\right), \quad \text { as } x_{0}<y_{0} \text { and } g\left(y_{0}\right)=25>k=F\left(y_{0}, x_{0}\right)
$$

Therefore, by Theorem 2.4, there exists $x, y \in X$ such that $g(x)=F(x, y)$ and $g(y)=F(y, x)$.

Corollary 2.6. Let $(X, \leq, d)$ be a partially ordered complete quasi-metric space with a $Q$-function $q$ on $X$. Suppose $F: X \times X \rightarrow X$ and $g: X \rightarrow X$ are such that $F$ has the mixed g-monotone property and assume that there exists $k \in(0,1)$ such that

$$
q(F(x, y), F(u, v)) \leq \frac{k}{2}[q(g(x), g(u))+q(g(y), g(v))]
$$

for all $x, y, u, v \in X$ for which $g(x) \leq g(u)$ and $g(y) \geq g(v)$. Suppose that $F(X \times X) \subseteq g(X)$, and $g$ is continuous and commutes with $F$, and also suppose that either

(a) $F$ is continuous or

(b) X has the following properties:

(i) if a nondecreasing sequence $\left\{x_{n}\right\} \rightarrow x$, then $x_{n} \leq x$ for all $n$,

(ii) if a nonincreasing sequence $\left\{y_{n}\right\} \rightarrow y$, then $y \leq y_{n}$ for all $n$.

If there exists $x_{0}, y_{0} \in X$ such that

$$
g\left(x_{0}\right) \leq F\left(x_{0}, y_{0}\right), \quad g\left(y_{0}\right) \geq F\left(y_{0}, x_{0}\right),
$$

then there exist $x, y \in X$ such that

$$
g(x)=F(x, y), \quad g(y)=F(y, x)
$$

that is, $F$ and $g$ have a coupled coincidence.

Proof. Taking $\varphi(t)=t$ in Theorem 2.4, we obtain Corollary 2.6.

Now, we will prove the existence and uniqueness theorem of a coupled common fixed point. Note that if $(S, \leq)$ is a partially ordered set, then we endow the product $S \times S$ with the 
Fixed Point Theory and Applications

following partial order:

$$
\text { for }(x, y),(u, v) \in S \times S, \quad(x, y) \leq(u, v) \Longleftrightarrow x \leq u, y \geq v \text {. }
$$

From Theorem 2.4, it follows that the set $C(F, g)$ of coupled coincidences is nonempty.

Theorem 2.7. The hypothesis of Theorem 2.4 holds. Suppose that for every $(x, y),\left(y^{*}, x^{*}\right) \in X \times X$ there exists $a(u, v) \in X \times X$ such that $(F(u, v), F(v, u))$ is comparable to $(F(x, y), F(y, x))$ and $\left(F\left(x^{*}, y^{*}\right), F\left(y^{*}, x^{*}\right)\right)$. Then, $F$ and $g$ have a unique coupled common fixed point; that is, there exist $a$ unique $(x, y) \in X \times X$ such that

$$
x=g(x)=F(x, y), \quad y=g(y)=F(y, x) .
$$

Proof. By Theorem, $2.1 C(F, g) \neq \phi$. Let $(x, y),\left(x^{*}, y^{*}\right) \in C(F, g)$. We show that if $g(x)=$ $F(x, y), g(y)=F(y, x)$ and $g\left(x^{*}\right)=F\left(x^{*}, y^{*}\right), g\left(y^{*}\right)=F\left(y^{*}, x^{*}\right)$, then

$$
g(x)=g\left(x^{*}\right), \quad g(y)=g\left(y^{*}\right)
$$

By assumption there is $(u, v) \in X \times X$ such that $(F(u, v), F(v, u))$ is comparable with $(F(x, y), F(y, x))$ and $\left(F\left(x^{*}, y^{*}\right), F\left(y^{*}, x^{*}\right)\right)$. Put $u_{0}=u, v_{0}=v$ and choose $u_{1}, v_{1} \in X$ so that $g\left(u_{1}\right)=F\left(u_{0}, v_{0}\right)$ and $g\left(v_{1}\right)=F\left(v_{0}, u_{0}\right)$. Then, as in the proof of Theorem 2.4, we can inductively define sequences $\left\{g\left(u_{n}\right)\right\}$ and $\left\{g\left(v_{n}\right)\right\}$ such that

$$
g\left(u_{n+1}\right)=F\left(u_{n}, v_{n}\right), \quad g\left(v_{n+1}\right)=F\left(v_{n}, u_{n}\right) .
$$

Further, set $x_{0}=x, y_{0}=y, x_{0}^{*}=x^{*}, y_{0}^{*}=y^{*}$, and, as above, define the sequences $\left\{g\left(x_{n}\right)\right\},\left\{g\left(y_{n}\right)\right\}$ and $\left\{g\left(x_{n}^{*}\right)\right\},\left\{g\left(y_{n}^{*}\right)\right\}$. Then it is easy to show that

$$
g\left(x_{n}\right)=F(x, y), \quad g\left(y_{n}\right)=F(y, x), \quad g\left(x_{n}^{*}\right)=F\left(x^{*}, y^{*}\right), \quad g\left(y_{n}^{*}\right)=F\left(y^{*}, x^{*}\right)
$$

for all $n \geq 1$. Since $(F(x, y), F(y, x))=\left(g\left(x_{1}\right), g\left(y_{1}\right)\right)=(g(x), g(y))$ and $(F(u, v), F(v, u))=$ $\left(g\left(u_{1}\right), g\left(v_{1}\right)\right)$ are comparable; therefore $g(x) \leq g\left(u_{1}\right)$ and $g(y) \geq g\left(v_{1}\right)$. It is easy to show that $(g(x), g(y))$ and $\left(g\left(u_{n}\right), g\left(v_{n}\right)\right)$ are comparable, that is, $g(x) \leq g\left(u_{n}\right)$ and $g(y) \geq g\left(v_{n}\right)$ for all 
$n \geq 1$. From (2.5) and properties of $\varphi$, we have

$$
\begin{aligned}
& q\left(g\left(u_{n+1}\right), g(x)\right)+q\left(g\left(v_{n+1}\right), g(y)\right) \\
&= q\left(F\left(u_{n}, y_{n}\right), F(x, y)\right)+q\left(F\left(v_{n}, u_{n}\right), F(y, x)\right) \\
& \leq k \varphi\left(\frac{q\left(g\left(u_{n}\right), g(x)\right)+q\left(g\left(y_{n}\right), g(y)\right)}{2}\right) \\
&+k \varphi\left(\frac{q\left(g\left(v_{n}\right), g(y)\right)+q\left(g\left(u_{n}\right), g(x)\right)}{2}\right) \quad(\text { by }(2.6)) \\
&= 2 k \varphi\left(\frac{q\left(g\left(u_{n}\right), g(x)\right)+q\left(g\left(v_{n}\right), g(y)\right)}{2}\right) \\
& \leq k\left(q\left(g\left(u_{n}\right), g(x)\right)+q\left(g\left(v_{n}\right), g(y)\right)\right) \\
& \leq k^{2} \varphi\left(\frac{q\left(g\left(u_{n-1}\right), g(x)\right)+q\left(g\left(v_{n-1}\right), g(y)\right)}{2}\right) \\
&+k^{2} \varphi\left(\frac{q\left(g\left(v_{n-1}\right), g(y)\right)+q\left(g\left(u_{n-1}\right), g(x)\right)}{2}\right) \quad(\text { by }(2.6)) \\
& \leq 2 k^{2} \varphi\left(\frac{q\left(g\left(v_{n-1}\right), g(y)\right)+q\left(g\left(u_{n-1}\right), g(x)\right)}{2}\right) \\
& \leq k^{2}\left(q\left(g\left(u_{n-1}\right), g(x)\right)+q\left(g\left(v_{n-1}\right), g(y)\right)\right) \\
& \leq k^{3} \varphi\left(\frac{q\left(g\left(u_{n-2}\right), g(x)\right)+q\left(g\left(v_{n-2}\right), g(y)\right)}{2}\right) \quad\left(\text { by } t_{0}(2.6)\right) \\
&+k^{3} \varphi\left(\frac{q\left(g\left(v_{n-2}\right), g(y)\right)+q\left(g\left(u_{n-2}\right), g(x)\right)}{2}\right) \\
& \ldots\left(\frac{q\left(g\left(u_{n-2}\right), g(x)\right)+q\left(g\left(v_{n-2}\right), g(y)\right)}{2}\right) \\
&
\end{aligned}
$$

where $t_{0}=q\left(g\left(u_{0}\right), g(x)\right)+q\left(g\left(v_{0}\right), g(y)\right)$. From this, it follows that, for each $n \in \mathbb{N}$,

$$
q\left(g\left(u_{n+1}\right), g(x)\right) \leq k^{n} t_{0}, \quad q\left(g\left(v_{n+1}\right), g(y)\right) \leq k^{n} t_{0} .
$$


Similarly, one can prove that

$$
q\left(g\left(u_{n+1}\right), g\left(x^{*}\right)\right) \leq k^{n} t_{0}^{\prime}, \quad q\left(g\left(v_{n+1}\right), g\left(y^{*}\right)\right) \leq k^{n} t_{0}^{\prime}, \quad n \in \mathbb{N},
$$

where $t_{0}^{\prime}=q\left(g\left(u_{0}\right), g\left(x^{*}\right)\right)+q\left(g\left(v_{0}\right), g\left(y^{*}\right)\right)$. Thus by Lemma 1.8, $g(x)=g\left(x^{*}\right)$ and $g(y)=$ $g\left(y^{*}\right)$. Since $g(x)=F(x, y)$ and $g(y)=F(y, x)$, by commutativity of $F$ and $g$, we have

$$
g(g(x))=g(F(x, y))=F(g(x), g(y)), \quad g(g(y))=g(F(y, x))=F(g(y), g(x)) .
$$

Denote $g(x)=z, g(y)=w$. Then from (2.61),

$$
g(z)=F(z, w), \quad g(w)=F(w, z)
$$

Thus, $(z, w)$ is a coupled coincidence point. Then, from (2.55), with $x^{*}=z$ and $y^{*}=w$, it follows that $g(z)=g(x)$ and $g(w)=g(y)$; that is,

$$
g(z)=z, \quad g(w)=w .
$$

From (2.62) and (2.63),

$$
z=g(z)=F(z, w), \quad w=g(w)=F(w, z)
$$

Therefore, $(z, w)$ is a coupled common fixed point of $F$ and $g$. To prove the uniqueness, assume that $(p, q)$ is another coupled common fixed point. Then, by $(2.55)$, we have $p=$ $g(p)=g(z)=z$ and $q=g(q)=g(w)=w$.

Corollary 2.8. Let $(X, \leq, d)$ be a partially ordered complete quasi-metric space with a $Q$-function $q$ on $X$. Assume that the function $\varphi:[0,+\infty) \rightarrow[0,+\infty)$ is such that $\varphi(t)<t$ for each $t>0$. Let $k \in(0,1)$, and let $F: X \times X \rightarrow X$ be a mapping having the mixed monotone property on $X$ and

$$
q(F(x, y), F(u, v)) \leq k \varphi\left(\frac{q(x, u)+q(y, v)}{2}\right), \quad \text { for each } x \leq u, y \geq v
$$

Also suppose that either

(a) $F$ is continuous or

(b) X has the following properties:

(i) if a nondecreasing sequence $\left\{x_{n}\right\} \rightarrow x$, then $x_{n} \leq x$ for all $n$,

(ii) if a non-increasing sequence $\left\{y_{n}\right\} \rightarrow y$, then $y \leq y_{n}$ for all $n$.

If there exists $x_{0}, y_{0} \in X$ such that

$$
x_{0} \leq F\left(x_{0}, y_{0}\right), \quad y_{0} \geq F\left(y_{0}, x_{0}\right),
$$


then, there exist $x, y \in X$ such that

$$
x=F(x, y), \quad y=F(y, x) .
$$

Furthermore, if $x_{0}, y_{0}$ are comparable, then $x=y$, that is, $x=F(x, x)$.

Proof. Following the proof of Theorem 2.4 with $g=I$ (the identity mapping on $X$ ), we get

$$
\begin{array}{cl}
x_{n}=g\left(x_{n}\right) \longrightarrow x, & y_{n}=g\left(y_{n}\right) \longrightarrow y, \\
x=F(x, y), & y=F(y, x) .
\end{array}
$$

We show that $x=y$. Let us suppose that $x_{0} \leq y_{0}$. We will show that $x_{n}, y_{n}$ are comparable for all $n \geq 0$, that is,

$$
x_{n} \leq y_{n}, \quad \forall n \geq 0,
$$

where $x_{n}=F\left(x_{n-1}, y_{n-1}\right), y_{n}=F\left(y_{n-1}, y_{n-1}\right), n \in\{1,2, \ldots\}$. Suppose that (2.69) holds for some fixed $n \geq 0$. Then, by mixed monotone property of $F$,

$$
x_{n+1}=F\left(x_{n}, y_{n}\right) \leq F\left(y_{n}, x_{n}\right)=y_{n+1}
$$

and (2.69) follows. Now from (2.69), (2.65), and properties of $\varphi$, we have

$$
\begin{aligned}
q\left(x_{n+1}, x\right) & =q\left(F\left(x_{n}, y_{n}\right), F(x, y)\right) \\
& \leq k \varphi\left(\frac{q\left(x_{n}, x\right)+q\left(y_{n}, y\right)}{2}\right) \\
& \leq k \frac{q\left(x_{n}, x\right)+q\left(y_{n}, y\right)}{2} \\
& \leq \frac{k}{2}\left(k \varphi\left(\frac{q\left(x_{n-1}, x\right)+q\left(y_{n-1}, y\right)}{2}\right)+k \varphi\left(\frac{q\left(y_{n-1}, y\right)+q\left(x_{n-1}, x\right)}{2}\right)\right) \\
& =k^{2} \varphi\left(\frac{q\left(x_{n-1}, x\right)+q\left(y_{n-1}, y\right)}{2}\right) \\
& \leq k^{3} \varphi\left(\frac{q\left(x_{n-2}, x\right)+q\left(y_{n-2}, y\right)}{2}\right) \\
& \leq \cdots \leq k^{n+1} \varphi\left(\frac{q\left(x_{0}, x\right)+q\left(y_{0}, y\right)}{2}\right)=k^{n+1} s_{0} \longrightarrow 0, \quad \text { as } n \longrightarrow \infty,
\end{aligned}
$$


where $s_{0}=\varphi\left(\left(q\left(x_{0}, x\right)+q\left(y_{0}, y\right)\right) / 2\right)$. Similarly, we get

$$
q\left(x_{n+1}, y\right)=q\left(F\left(x_{n}, y_{n}\right), F(y, x)\right) \leq k^{n+1} w_{0} \longrightarrow 0, \quad \text { as } n \longrightarrow \infty,
$$

where $w_{0}=\varphi\left(\left(q\left(x_{0}, y\right)+q\left(y_{0}, x\right)\right) / 2\right)$. Hence, by Lemma 1.8, $x=y$, that is, $x=F(x, x)$.

Corollary 2.9. Let $(X, \leq, d)$ be a partially ordered complete quasi-metric space with a $Q$-function $q$ on $X$. Let $F: X \times X \rightarrow X$ be a mapping having the mixed monotone property on $X$. Assume that there exists a $k \in(0,1)$ such that

$$
q(F(x, y), F(u, v)) \leq \frac{k}{2}[q(x, u)+q(y, v)], \text { for each } x \leq u, y \geq v
$$

Also, suppose that either

(a) $F$ is continuous or

(b) X has the following properties:

(i) if a nondecreasing sequence $\left\{x_{n}\right\} \rightarrow x$, then $x_{n} \leq x$ for all $n$,

(ii) if a nonincreasing sequence $\left\{y_{n}\right\} \rightarrow y$, then $y \leq y_{n}$ for all $n$.

If there exists $x_{0}, y_{0} \in X$ such that

$$
x_{0} \leq F\left(x_{0}, y_{0}\right), \quad y_{0} \geq F\left(y_{0}, x_{0}\right),
$$

then, there exist $x, y \in X$ such that

$$
x=F(x, y), \quad y=F(y, x) .
$$

Furthermore, if $x_{0}, y_{0}$ are comparable, then $x=y$, that is, $x=F(x, x)$.

Proof. Taking $\varphi(t)=t$ in Corollary 2.8, we obtain Corollary 2.9.

Remark 2.10. As an application of fixed point results, the existence of a solution to the equilibrium problem was considered in [2-7]. It would be interesting to solve Ekeland-type variational principle, Ky Fan type best approximation problem and equilibrium problem utilizing recent results on coupled fixed points and coupled coincidence points.

\section{Acknowledgment}

The first and third author are grateful to DSR, King Abdulaziz University for supporting research project no. (3-74/430). 


\section{References}

[1] R. P. Agarwal, M. A. El-Gebeily, and D. O’Regan, “Generalized contractions in partially ordered metric spaces," Applicable Analysis, vol. 87, no. 1, pp. 109-116, 2008.

[2] S. Al-Homidan, Q. H. Ansari, and J.-C. Yao, "Some generalizations of Ekeland-type variational principle with applications to equilibrium problems and fixed point theory," Nonlinear Analysis: Theory, Methods E Applications, vol. 69, no. 1, pp. 126-139, 2008.

[3] Q. H. Ansari, "Vectorial form of Ekeland-type variational principle with applications to vector equilibrium problems and fixed point theory," Journal of Mathematical Analysis and Applications, vol. 334, no. 1, pp. 561-575, 2007.

[4] Q. H. Ansari, I. V. Konnov, and J. C. Yao, "On generalized vector equilibrium problems," Nonlinear Analysis: Theory, Methods \& Applications, vol. 47, no. 1, pp. 543-554, 2001.

[5] Q. H. Ansari, A. H. Siddiqi, and S. Y. Wu, "Existence and duality of generalized vector equilibrium problems," Journal of Mathematical Analysis and Applications, vol. 259, no. 1, pp. 115-126, 2001.

[6] Q. H. Ansari and J.-C. Yao, "An existence result for the generalized vector equilibrium problem," Applied Mathematics Letters, vol. 12, no. 8, pp. 53-56, 1999.

[7] Q. H. Ansari and J.-C. Yao, "A fixed point theorem and its applications to a system of variational inequalities," Bulletin of the Australian Mathematical Society, vol. 59, no. 3, pp. 433-442, 1999.

[8] T. G. Bhaskar and V. Lakshmikantham, "Fixed point theorems in partially ordered metric spaces and applications," Nonlinear Analysis: Theory, Methods \& Applications, vol. 65, no. 7, pp. 1379-1393, 2006.

[9] T. G. Bhaskar, V. Lakshmikantham, and J. Vasundhara Devi, "Monotone iterative technique for functional differential equations with retardation and anticipation," Nonlinear Analysis: Theory, Methods E Applications, vol. 66, no. 10, pp. 2237-2242, 2007.

[10] D. W. Boyd and J. S. W. Wong, "On nonlinear contractions," Proceedings of the American Mathematical Society, vol. 20, pp. 458-464, 1969.

[11] Lj. B. Cirić, "A generalization of Banach's contraction principle," Proceedings of the American Mathematical Society, vol. 45, no. 2, pp. 267-273, 1974.

[12] L. Cirić, "Fixed point theorems for multi-valued contractions in complete metric spaces," Journal of Mathematical Analysis and Applications, vol. 348, no. 1, pp. 499-507, 2008.

[13] L. Ćirić, N. Hussain, and N. Cakić, "Common fixed points for Ćirić type $f$-weak contraction with applications," Publicationes Mathematicae Debrecen, vol. 76, no. 1-2, pp. 31-49, 2010.

[14] Lj. B. Ćirić and J. S. Ume, "Multi-valued non-self-mappings on convex metric spaces," Nonlinear Analysis: Theory, Methods \& Applications, vol. 60, no. 6, pp. 1053-1063, 2005.

[15] L. Gajić and V. Rakočević, "Quasicontraction nonself-mappings on convex metric spaces and common fixed point theorems," Fixed Point Theory and Applications, no. 3, pp. 365-375, 2005.

[16] D. J. Guo and V. Lakshmikantham, Nonlinear Problems in Abstract Cones, vol. 5 of Notes and Reports in Mathematics in Science and Engineering, Academic Press, Boston, Mass, USA, 1988.

[17] S. Heikkilä and V. Lakshmikantham, Monotone Iterative Techniques for Discontinuous Nonlinear Differential Equations, vol. 181 of Monographs and Textbooks in Pure and Applied Mathematics, Marcel Dekker, New York, NY, USA, 1994.

[18] N. Hussain, "Common fixed points in best approximation for Banach operator pairs with Cirić type I-contractions," Journal of Mathematical Analysis and Applications, vol. 338, no. 2, pp. 1351-1363, 2008.

[19] N. Hussain, V. Berinde, and N. Shafqat, "Common fixed point and approximation results for generalized $\phi$-contractions," Fixed Point Theory, vol. 10, no. 1, pp. 111-124, 2009.

[20] N. Hussain and M. A. Khamsi, "On asymptotic pointwise contractions in metric spaces," Nonlinear Analysis: Theory, Methods E Applications, vol. 71, no. 10, pp. 4423-4429, 2009.

[21] O. Kada, T. Suzuki, and W. Takahashi, "Nonconvex minimization theorems and fixed point theorems in complete metric spaces," Mathematica Japonica, vol. 44, no. 2, pp. 381-391, 1996.

[22] M. A. Khamsi and W. A. Kirk, An Introduction to Metric Spaces and Fixed Point Theory, Pure and Applied Mathematics, Wiley-Interscience, New York, NY, USA, 2001.

[23] V. Lakshmikantham, T. G. Bhaskar, and J. Vasundhara Devi, Theory of Set Differential Equations in Metric Spaces, Cambridge Scientific Publishers, Cambridge, UK, 2006.

[24] V. Lakshmikantham and L. Ćirić, "Coupled fixed point theorems for nonlinear contractions in partially ordered metric spaces," Nonlinear Analysis: Theory, Methods E Applications, vol. 70, no. 12, pp. 4341-4349, 2009.

[25] V. Lakshmikantham and S. Köksal, Monotone Flows and Rapid Convergence for Nonlinear Partial Differential Equations, vol. 7 of Series in Mathematical Analysis and Applications, Taylor \& Francis, London, UK, 2003. 
[26] V. Lakshmikantham and A. S. Vatsala, "General uniqueness and monotone iterative technique for fractional differential equations," Applied Mathematics Letters, vol. 21, no. 8, pp. 828-834, 2008.

[27] L.-J. Lin and W.-S. Du, "Ekeland's variational principle, minimax theorems and existence of nonconvex equilibria in complete metric spaces," Journal of Mathematical Analysis and Applications, vol. 323, no. 1, pp. 360-370, 2006.

[28] J. J. Nieto and R. Rodríguez-López, "Contractive mapping theorems in partially ordered sets and applications to ordinary differential equations," Order, vol. 22, no. 3, pp. 223-239, 2005.

[29] J. J. Nieto and R. Rodríguez-López, "Existence and uniqueness of fixed point in partially ordered sets and applications to ordinary differential equations," Acta Mathematica Sinica (English Series), vol. 23, no. 12, pp. 2205-2212, 2007.

[30] A. C. M. Ran and M. C. B. Reurings, "A fixed point theorem in partially ordered sets and some applications to matrix equations," Proceedings of the American Mathematical Society, vol. 132, no. 5, pp. 1435-1443, 2004.

[31] B. K. Ray, “On Ciric's fixed point theorem," Fundamenta Mathematicae, vol. 94, no. 3, pp. 221-229, 1977. 